\title{
Community healthcare workers' satisfaction with ward-based outreach team services in Tshwane district, South Africa
}

\author{
JV Ndimande*, GA Ogunbanjo (D), SN Nyalunga, A Masango-Makgobela and T Bongongo \\ Discipline of Family Medicine, Sefako Makgatho Health Sciences University, Garankuwa, Tshwane, South Africa \\ *Corresponding author, email: ndimandejv@gmail.com
}

Background: The incorporation of community healthcare worker (CHW) involvement in the management of patients is in line with the 2006 World Health Report, which advocates increased community participation and the systematic delegation of tasks to less specialised cadres. For CHWs to function optimally, satisfaction in their duties is paramount to promote quality healthcare. The health minister included ward-based outreach teams (WBOT) as part of the National Health Insurance. ${ }^{1}$ CHWs form an important link between healthcare facilities and the communities. This study aimed to measure the satisfaction level of the CHWs with WBOT services in the Tshwane district of South Africa.

Method: A cross-sectional study on CHWs was conducted in seven sub-districts. Data were obtained by trained data collectors using a piloted self-administered structured questionnaire from October 12 to November 3, 2015 in three local official languages. The study population of CHWs was 1600 . Using a $95 \%$ confidence level and $5 \%$ confidence interval, the sample size was 310. However, we over-sampled to 431 participants.

Results: The mean age was 36 years $(S D \pm 9.46)$. The majority were females $(82.1 \%)$; more than three-quarters $(77 \%)$ had secondary education. The majority were satisfied with the WBOT services whereby $59.8 \%$ was the lowest score and $98.4 \%$ the highest score. Close to two-thirds (62\%) were not satisfied with their monthly stipends. The majority of the younger members of the team (20-40 years) were not valued by their co-workers $(70 \%$ or $181 / 255)$ [ $p=0.03]$. The overall satisfaction $(n=8593)$ was $73.4 \%(p<0.001)$.

Conclusion: Overall satisfaction of CHWs with WBOT is good news. Dissatisfaction regarding stipend/compensation must be addressed. CHWs should be valued and motivated.

Keywords: community, National Health Insurance (NHI), satisfaction, ward-based outreach teams

\section{Background}

Community healthcare workers (CHWs) are primary and close contact public health workers who understand and are supposedly part of the communities they serve. They are trusted liaison officers, forming a link and acting as protectors of their communities. They are intermediaries between health and/or social services. There are certain expectations from this cadre of healthcare providers such as understanding the social determinants of health, facilitating access through outreach, community education, informal counselling and social support. While CHWs are not medical professionals they are essential healthcare providers and it is important that they are satisfied in their work and that they receive the support they deserve with minimal stress related to service delivery. ${ }^{2}$ Satisfaction in this research means conditions under which CHWs work in order to meet the objectives of the $\mathrm{NHI}$, to fulfil expectations of the communities they are intended to serve, satisfaction from the health system they work for and from their own organisation.

The need to have CHWs in many countries comes as a result of a number of challenges, such as ageing professional health workers, migration for better paying jobs without them being replaced by younger ones, the growing populations, and the increased burden of disease, especially non-communicable diseases. This staff shortage currently stands at 7.5 million globally. ${ }^{3}$

The incorporation of $\mathrm{CHWs}^{\prime}$ involvement in the management of patients is in line with the 2006 World Health Report, which advocates increased community participation and the systematic delegation of tasks to less specialised cadres. However, this has not gone unchallenged as there have been debates regarding the expediency, efficacy and modalities of task shifting. This delegation of tasks from one cadre to another is called substitution and is not a new concept. It has been used in many countries and for many decades, either as a response to emergence of diseases, or as a need to cope with provision of adequate care at primary (community), secondary and tertiary levels, especially in understaffed rural facilities, to enhance quality at reduced and effective costs. ${ }^{4}$

The 2006 World Health Report estimated that 57 countries, particularly sub-Saharan Africa, faced critical shortages of health personnel totalling 2.4 million doctors, nurses and midwives. The WHO estimates that there is a global shortage of about 4.3 million healthcare workers, a shortfall of about $15 \% .^{5}$ In France and Germany, for example, the density of physicians per 10000 populations was 32 and 39, respectively, over the period 2007-2013, whereas in a number of African countries it was less than 1 per 10000 population. ${ }^{6}$

A study conducted in Norway by Mickkelsen et al. identified main stressors in the workplace as sources for dissatisfaction among CHWs. This study was done through identification of $\mathrm{CHWs}^{\prime}$ own perceptions of work-related stressors. The aim of the study sought ways to improve the organisation where they were providing health services. The dissatisfactions and stressors in the organisation were found to be related to lack of information and communication, lack of respect among professions and lack of professional and personal development within the organisation. ${ }^{7}$ 
HIV has become one of the major diseases debilitating communities in Africa. In the sub-Saharan countries of Ethiopia, Malawi and Uganda, appraisal of six community health worker programmes showed that antiretroviral treatment-specific opportunities are not being sufficiently seized due to dissatisfaction where CHWs are particularly involved in task sharing in the provision of antiretrovirals (ARVs). Without adequate remuneration it was found that CHWs cannot be retained in the long term. ${ }^{8}$

Sub-Saharan Africa has problems of outbreak diseases such as Ebola and haemorrhagic conditions and this has prompted calls and support for an increase in the number of trained CHWs, the need to understand where these workers are and where coverage gaps exist. Direct Relief and Esri developed a map to track the availability of community health workers in sub-Saharan Africa. The ' 1 Million Community Health Workers Campaign' is a collaboration between the United Nations and the Earth Institute at Columbia University, which aims to expand community health worker programmes across the region. ${ }^{9,10}$

One of the major challenges that affect service delivery in subSaharan countries is the fact that salaries are fixed and are not linked to the provision of services. There are few incentives to motivate health workers to be responsive to the communities for which they provide services. ${ }^{11}$

South Africa remains one of the most unequal societies globally, $^{12}$ necessitating consideration of relying on CHWs to provide health care to these needy communities who generally cannot afford expensive medical care nor have medical aid. According to new data released by Stats SA, poverty is on the rise in South Africa. The latest 'Poverty Trends in South Africa' report shows that, despite the general decline in poverty between 2006 and 2011, poverty levels in South Africa rose in 2015. More than half of South Africans were poor in 2015, with the poverty headcount increasing to $55.5 \%$ from a series low of $53.2 \%$ in 2011. The figures are calculated using the upper-bound poverty line (UBPL) of R992 per person per month (pppm) at 2015 prices. This translates to over 30.4 million South Africans living in poverty in $2015 .^{13}$

South Africa has embarked on a new healthcare delivery model with its National Health System following the release of its green paper on Policy on National Health Insurance (NHI) on August 11,2011 . The $\mathrm{NHI}$ intends to ensure that the community has access to appropriate, efficient and quality health services. NHI proposes four key interventions: (i) a complete transformation of healthcare service provision and delivery; (ii) the total overhaul of the healthcare system; (iii) a radical change of administration and management; (iv) the provision of a comprehensive package of care underpinned by a re-engineered primary health care, which is currently plagued by a shortage of key human resources in the health sector and in particular the public sector. ${ }^{14}$

Tshwane health district was among the pilot study districts piloted for the national health service in the financial year 2012-2014. CHWs within a programme called 'Ward Based Outreach Teams' (WBOT) have been working in the communities, thus this study aimed to assess their satisfaction level while working in the respective communities.

\section{Method}

This was a cross-sectional study. From a total of $1600 \mathrm{CHWs}$ and using a $95 \%$ confidence level and $5 \%$ confidence interval, the sample size worked out to $310 \mathrm{CHWs}$. A total of $431 \mathrm{CHWs}$ were studied as the questionnaires were given to all those CHWs who were on duty on the days of the visit at their base facilities, and who met the criteria for inclusion of being above 18 years of age with a minimum experience of six months of service. A total of 19 primary health facilities that were linked to WBOTs were included in the study. We trained data collectors for a week to familiarise them with the study and to familiarise them with the questionnaire. A pilot was conducted in one clinic which did not form part of the main study.

We visited each of the seven sub-districts of Tshwane health district. Any CHW who was on duty on the day of data collection was selected for the study if he/she consented and had been employed for more than six months. Data were collected using a structured questionnaire consisting of 20 piloted questions regarding employee satisfaction. The questionnaire was based on surveys on job satisfaction by employees and concerns from the national government ${ }^{15}$ and tailored in accordance with media complaints and industrial action in South Africa on the part of CHWs depending on the Department of Health. Negative feelings about work such as poor working conditions, overwork, low levels of pay, no scope for promotion or career advancement and lack of recognition are some issues that could lead to job dissatisfaction. ${ }^{2}$ The first part of the questionnaire consisted of the baseline data, which included age, gender, marital status and highest educational level. The second part comprised satisfaction-level questions with a scoring scale ranging from 1 to 3 , where $1=$ agree, 2 = disagree, $3=$ indifferent. Data were collected from October 12 to November 3, 2015 by trained data collectors. Data were captured into a Microsoft Excel ${ }^{\oplus}$ spreadsheet (Microsoft Corp, Redmond, WA, USA) and analysed using SAS version 9.2 (SAS Institute, Cary, NC, USA) by a statistician. The significance level was set at $p \leq$ 0.05 . Using univariate and bivariate analysis, we compared scores by their $95 \%$ confidence level and $5 \%$ interval. Informed consent was obtained. The questionnaire was completed anonymously by the CHWs. Ethics approval was obtained from Sefako Makgatho University Research Ethics committee (SMUREC) with number SMUREC/114/2015: IR.

\section{Results}

A total of $431 \mathrm{CHWs}$ formed the sample. For age, data were available from 425 participants, with a mean age of 36 years (SD \pm 9.46), ranging between 21 and 66 years. Slightly above onethird (36\%) of participants were in the age group 31-40 years. The majority $(88.2 \%$; 380/431) were females. Of the 426 participants who responded to their marital status, $69.3 \%$ were single. Over three-quarters $(77.0 \%)$ had completed secondarylevel education (Table 1).

Of 19 questions assessing satisfaction (Table 2), the majority on each of the 19 questions were satisfied with the WBOT services, ranging from the lowest percentage at $59.9 \%$ to highest percentage at $98.4 \%$ strongly agreeing for each of the satisfaction-level questions. The majority $(98.4 \% n=424)$ understand the roles and duties of the organisation (WBOT). The lowest satisfaction rate of $59.9 \%(n=355)$ of respondents was found regarding 'decision making and delegation principles' (Question 10 in Table 2). The majority (93.7\%) were valued by team members as well as in return having value for their team members (97.4\% $n=420)$. The implication is that the CHWs in WBOT enjoy teamwork and are united. Slightly more than two-thirds $(65.8 \%$ 280/426) were not satisfied with compensation for the work they were doing. 
Table 1: Baseline characteristics

\begin{tabular}{|c|c|c|}
\hline Variables & Categories & $\begin{array}{c}\text { Frequency } \\
\text { (percentage) }\end{array}$ \\
\hline \multirow{5}{*}{$\begin{array}{l}\text { Age } \\
(n=425)\end{array}$} & $21-30$ & $129(30.4)$ \\
\hline & $31-40$ & $153(36)$ \\
\hline & $41-50$ & $103(24.2)$ \\
\hline & $51-60$ & $38(8.9)$ \\
\hline & $>60$ & $2(0.5)$ \\
\hline \multirow{2}{*}{$\begin{array}{l}\text { Sex } \\
(n=431)\end{array}$} & Female & $380(88.2)$ \\
\hline & Male: & $51(11.8)$ \\
\hline \multirow{4}{*}{$\begin{array}{l}\text { Marital status } \\
(n=426)\end{array}$} & Single & $295(69.3)$ \\
\hline & Married & $116(27.2)$ \\
\hline & Divorced & $9(2.1)$ \\
\hline & Widowed & $6(1.4)$ \\
\hline \multirow{3}{*}{$\begin{array}{l}\text { Highest educational } \\
\text { qualification } \\
(n=426)\end{array}$} & Primary & $10(2.4)$ \\
\hline & Secondary & $328(77)$ \\
\hline & Tertiary & $87(20.4)$ \\
\hline
\end{tabular}

Question 4 asked respondents about been valued by co-workers and the majority really feel valued. However, Table 3 shows that the majority of the younger members of the team (20-40 years) report that they are not valued by their co-workers (70\% or 177 / 252). The chi-square statistic is 4.4466 . The $p$-value is 0.034971 . This result is significant at $p \leq 0.05$.

Table 4 shows the relationship between age and stipend received by the CHWs, where all age bands show dissatisfaction with the stipend through either disagreeing or being indifferent towards the stipend they receive. The most dissatisfied group is found in the age band $31-40$ years. The chi-square statistic is 6.4834. The $p$-value is 0.371265 . The result is not statistically
Table 3: Age and being valued by the team members $(n=410)$

\begin{tabular}{lccc}
\hline $\begin{array}{l}\text { Age } \\
\text { groups }\end{array}$ & $\begin{array}{c}\text { Agree } \\
\text { frequency }\end{array}$ & $\begin{array}{c}\text { Disagree and } \\
\text { indifferent } \\
\text { frequency }\end{array}$ & $\begin{array}{c}\text { Marginal } \\
\text { row totals }\end{array}$ \\
\hline $\begin{array}{l}20-40 \\
\text { years }\end{array}$ & 95 & 177 & 272 \\
$>40$ & 63 & 75 & 138 \\
years & 158 & 252 & 410 \\
\hline Total & & & \\
\hline
\end{tabular}

The chi-square statistic is 4.4466 . The $p$-value is 0,034971 . This result is significant at $p \leq 0.05$.

significant at $p \leq 0.05$. While this is so, this age group is generally regarded as being in the the period when individuals face serious socioeconomic challenges.

According to Table 5, there was no statistical significance between primary and higher education in response to 'adequate training and development opportunities to improve their skills' in the WBOT programme.

Fisher's exact test statistical value is 1 . The result is not significant at $p \leq 0.05$.

While close to three-quarters of the respondents are satisfied with 'decision-making and delegation of duty' Table 6 shows no statistical significance between age and 'decision-making and delegation of duty' $(p=0.58)$. The chi-square statistic is 1.0645 . The $p$-value is 0.587296 . The result is not significant at $p \leq 0.05$.

Table 7 shows the overall satisfaction on all 20 questions concerning satisfaction, taking into account all $\mathrm{CHW}$ responses $(n$

Table 2: Responses received from CHWs concerning satisfaction

\begin{tabular}{|c|c|c|c|}
\hline Questions & $\begin{array}{l}\text { Agree Frequency } \\
\qquad(\%)\end{array}$ & $\begin{array}{l}\text { Disagree } \\
\text { Frequency (\%) }\end{array}$ & $\begin{array}{l}\text { Indifferent } \\
\text { Frequency (\%) }\end{array}$ \\
\hline 1. Do you understand your duties and roles in the organisation? $(n=431)$ & $424(98.4)$ & $4(0.9)$ & $3(0.7)$ \\
\hline 2. Is your relationship with management based on trust? $(n=431)$ & $354(82.1)$ & $63(14.6)$ & $14(3.3)$ \\
\hline 3. Do you value your co-workers? $(n=431)$ & $420(97.5)$ & $8(1.8)$ & $3(0,7)$ \\
\hline 4. Do you feel valued by your co-workers? $(n=431)$ & $404(93.7)$ & $21(0.9)$ & $6(1.4)$ \\
\hline 5. Is information communicated effectively? $(n=431)$ & $317(73.6)$ & $105(6.4)$ & $9(2.1)$ \\
\hline 6. Do you believe you have a voice in the organisation? $(n=427)$ & $274(64.2)$ & $135(31.6)$ & $18(4.2)$ \\
\hline 7. Is there fairness in evaluation of your performance? $(n=429)$ & $279(65.0)$ & $127(29.6)$ & $23(5.3)$ \\
\hline 8. Are you adequately rewarded for your service? $(n=426)$ & $146(34.3)$ & $264(62)$ & $16(3.8)$ \\
\hline $\begin{array}{l}\text { 9. Are you provided with adequate training and development opportunities to } \\
\text { improve your skills? }(n=430)\end{array}$ & $339(78.8)$ & $82(19.1)$ & $9(2.1)$ \\
\hline 10. Are decision-making and delegation principles effective? $(n=355)$ & $257(59.8)$ & $82(36.5)$ & $16(3.7)$ \\
\hline 11. Are you encouraged to be creative and express new ideas? $(n=430)$ & $283(65.8)$ & $131(30.5)$ & $16(3.7)$ \\
\hline 13. Are you encouraged to be a team player? $(n=431)$ & $342(79.4)$ & $81(18.8)$ & $8(1.9)$ \\
\hline 14. Do you receive the support needed to perform effectively? $(n=419)$ & $286(66.7)$ & $134(31.2)$ & $9(2.1)$ \\
\hline $\begin{array}{l}\text { 15. Are you satisfied with the quality of service provided by your teamwork and } \\
\text { the organisation? }(n=431)\end{array}$ & $261(60.6)$ & $158(36.7)$ & $12(2.8)$ \\
\hline 16. Is there fairness by management in handling your conflicts? $(n=431)$ & $279(64.7)$ & $140(32.5)$ & $12(2.8)$ \\
\hline 17. Are innovative solutions used to prevent conflicts? $(n=428)$ & $284(66.4)$ & $133(31.1)$ & $11(2.6)$ \\
\hline 18. Are you motivated to perform well? $(n=426)$ & $343(80.5)$ & $83(19.5)$ & $5(1.2)$ \\
\hline 19. Is your morale high? $(n=425)$ & $332(78.1)$ & $83(19.5)$ & $10(2.4)$ \\
\hline 20. Do you understand the overall visions and goals? $(n=430)$ & $392(91.2)$ & $30(7)$ & $8(1.9)$ \\
\hline
\end{tabular}


Table 4: Relationship between age and stipend $(n=407)$

\begin{tabular}{lcccc}
\hline Age groups & Agree & Do not agree & Indifferent & Total \\
\hline $20-30$ & 38 & 32 & 53 & 123 \\
$31-40$ & 50 & 46 & 50 & 146 \\
$41-50$ & 39 & 27 & 33 & 99 \\
$>50$ & 11 & 16 & 12 & 39 \\
Total & 138 & 121 & 148 & 407 \\
\hline
\end{tabular}

Table 5: Educational status vs. adequate training and development opportunities to improve skills

\begin{tabular}{lcc}
\hline Education status & Agree & Do not agree \\
\hline Primary education & 3 & 6 \\
Secondary and tertiary & 121 & 231 \\
Marginal column totals & 124 & 237 \\
\hline
\end{tabular}

Table 6: Relationship between age and 'decision making and delegation of duty'

\begin{tabular}{lccc}
\hline Age groups & Agree & Disagree & Unsure \\
\hline $20-40$ years & 171 & 81 & 36 \\
$>40$ years & 82 & 43 & 13 \\
\hline
\end{tabular}

Table 7: Overall satisfaction

\begin{tabular}{lcccc}
\hline$n$ & Yes & No & Z & $p$-value \\
\hline 8593 & 73.4 & 26.6 & 43.46 & $<0.001$ \\
\hline
\end{tabular}

$=8593)$. The overall satisfaction results were calculated as $73.4 \%$ $(p<0.001)$.

\section{Discussion}

The study showed that the majority of CHWs are females. According to Stats South Africa the community and social services sector is the most common sector of employment among women (28.7\%) while the most common sector among men is trade $(21.1 \%)$. A large proportion of employment among the South African community is by government departments. ${ }^{16}$

This study showed that the CHWs in the Tshwane NHI pilot study were satisfied with the WBOT services, with $60-98.4 \%$ strongly agreeing with the satisfaction questions.

A study conducted in Swaziland by Geldsetzer et al. looked at improving the performance of CHWs. There were similar concerns raised by the CHWs, namely monetary compensation, a more reliable supply of clinical and personal equipment to CHWs, additional training and an extension of CHWs' responsibilities to cover a wider range of the community's healthcare needs. In contrast, the CHWs suggested changes to the programme's supervision structure, opportunities for career progression and $\mathrm{CHWs}^{\prime}$ relationship with the community. ${ }^{17}$

WBOT is supposed to directly impact patient care in primary health re-engineering of the NHI. While our study did not focus on the link between CHW satisfaction and patient satisfaction, Janicijevic et al. ${ }^{18}$ conducted a study in Serbia that focused on this link and found the correlation to be relatively low. However, they concluded that this correlation, especially regarding the time $\mathrm{CHWs}$ spend out in the communities on their assigned tasks, has the greatest effect on patient care and cannot be neglected.

While most of the CHWs were satisfied, we noted that there were those expressing dissatisfaction and these individuals cannot be neglected. It is common for employees to feel dissatisfied in the workplace sometimes. Some will leave their employment for better opportunities, while others will stay and remain unhappy. ${ }^{19}$ Noteworthy is the significant dissatisfaction related to compensation/stipend, where two-thirds of CHWs (62\%) were dissatisfied with the stipend received. A study conducted by Akwataghibe et al. in Nigeria demonstrated dissatisfaction among healthcare workers regarding their salaries. ${ }^{20}$ While there is dissatisfaction regarding remuneration, there is no statistical relationship between age and the stipend received ( $p$ -0.371265 .) While this is so, this age group is generally regarded as being in the period when individuals face serious socioeconomic challenges.

McCord et al. ${ }^{10}$ did a study in sub-Saharan Africa to cost the CHW worker programme in relation to the primary health system. The study regarded the community health worker programme as a sub-system of the primary health care system and concluded that a comprehensive CHW sub-system can be deployed in sub-Saharan countries at a cost that is modest within the projected costs of the primary health system. A well-developed CHW sub-system would be an advantage, especially considering the resource constraints and financial challenges of sub-Saharan Africa. The success of the primary health leveraging on CHWs assumed that they receive short training and strong supervision to strengthen patients' access to health. In the WBOT programme CHWs were provided with a short course training of 69 days, which was sponsored by the Foundation for Professional Development, which is a US programme for HIV treatment.

South Africa is facing serious health challenges, especially in reaching needy communities, thus explaining the initiative by the South African health minister towards the NHI.

The WHO has made recommendations on remuneration of CHWs, especially in low-income countries. Most successful programmes pay CHWs well. There is little evidence to show that voluntarism is sustainable over a long period of time. Adequate compensation improves motivation, performance and retention. Fair and consistent wages for every worker guarantees a stable income and the livelihood of CHWs. ${ }^{21}$

Mpembeni et al. conducted a similar study in Tanzania on factors of CHW satisfaction. Surveys of 238 eligible CHWs were studied. The study measured motivation and satisfaction regarding training and supervision, availability of equipment and supplies, interpersonal relationships at work and remuneration. Like our study, respondents showed some level of satisfaction and motivation towards community work due to altruism and intrinsic needs: eagerness to serve the community by improving the health of the population, as well as taking pride in their own work. Their study showed that older and less educated CHWs were more likely to be motivated by altruism, intrinsic needs and skill utilisation, community respect and hope for employment. $^{22}$ 
The limitation of this study is that we did not interview the coordinators of the WBOT and the NHI managers to gain their views, which might have presented another view of the CHWs. We should have included the Integrated School Health Programme (ISHP) and Maternal Neonatal Child Woman's Health (MNCWH) CHWs.

\section{Conclusion and recommendations}

The findings of this study showed some level of $\mathrm{CHW}$ satisfaction regarding the WBOT services. The fact that there is an element of dissatisfaction on all questions means much still has to be done. As the majority of participants are female, relatively young individuals in their prime years, it is paramount to have systems that address remuneration in line with the demands made by the general South African population. Taking care of $\mathrm{CHWs}$ has the potential to improve access to health. Like professional healthcare workers, their training is of paramount importance in promoting NHI. The National Department of Health (NDoH) must do its best to investigate remuneration packages of $\mathrm{CHWs}$ sooner rather than later for $\mathrm{NHI}$ to be a success.

Acknowledgement - The staff of the Department of Family Medicine of Sefako Makgatho Health Sciences University (SMU) thank the Tshwane district department of health, through the $\mathrm{NHI}$ committee under the leadership of the district director $\mathrm{Mr}$ Mothomone Pitsi, for funding this project. The authors would also like to thank statistician Professor Schoeman for analysing the data, Mr Stevens Kgoebane who managed the data, the data collectors and data capturers, and the participants, who made the study possible.

Disclosure statement - No potential conflict of interest was reported by the authors.

\section{ORCID}

GA Ogunbanjo (D) http://orcid.org/0000-0002-8256-6571

\section{References}

1. Pillay $Y$, Barron P. The implementation of $P H C$ re-engineering in South Africa. Summary drawn from the Provincial Guidelines for the Implementation of the Three Streams of PHC Reengineering, National Department of Health, South Africa. [Internet]. 2012 [cited 2017 June 25]. Available from: https://www.phasa.org.za/wpcontent/uploads/2011/11/Pillay-The-implementation-of-PHC.pdf

2. Community Health Worker. [Internet]. Available from: https:// explorehealthcareers.org/career/allied-health-professions/ community-health-worker/

3. World Health Organization (WHO). Global health workforce shortage to reach 12.9 million in coming decades. [Internet]. 2013 [cited 2017 June 25]. Available from: http://www.who.int/mediacentre/news/ releases/2013/health-workforce-shortage/en/

4. Lehmann U, Van Damme W, Barten F, Sanders D. Task shifting: the answer to the human resources crisis in Africa? [Internet]. Hum Resour Health. 2009;7:14 [accessed 13 October 2017]. https://doi. org/10.1186/1478-4491-7-49.

5. World Health Organization (WHO). Working together for health: the world health report 2006. [Internet]. Geneva: World Health Organization; 2006. [cited2017 Oct 19]. Available from: http://www. who.int/healthsystems/topics/health-law/chapter14.pdf

6. World Health Organization (WHO). Health systems financing: the path to universal coverage. [Internet]. Geneva: World Health Organization; 2010. Available from: http://www.who.int/healthsystems/topics/ health-law/chapter14.pdf
7. Mickkelsen A, Saksvik PO, Landsbergis P. Work and stress. The impact of a participatory organizational intervention on job stress in community health care institutions Tailor and Francis. $J$ Work Health Organ. 2000;14(2):156-70.

8. Hermann K, Van Damme W, Pariyo G, Schouten E, Assefa Y, Cirera A, et al. Community health workers for ART in sub-Saharan Africa: learning from experience - capitalizing on new opportunities. [Internet]. Hum Resour Health. 2009;7:31. [cited 2017 Oct 13]. https://doi.org/ 10.1186/1478-4491-7-31

9. Tony M. A map of community health workers in sub-Saharan Africa. [Internet]. 2014 [cited 2014 July 14]. Available from: https://www. directrelief.org/2014/10/map-of-community-health-workers-inafrica/

10. McCord GC, Liu A, Singh P. Deployment of community health workers across rural sub-Saharan Africa: financial considerations and operational assumptions. [Internet]. 2013 [cited 2013 Oct 13]. Available from: https://www.who.int/bulletin/volumes/91/4/12109660/en/

11. World Bank Group. Improving primary health care delivery in Nigeria: evidence from four states. Washington: World Bank; 2010. (World Bank Working Paper No. 187) in Akwataghibe N, Samaranayake D Lemiere $C$, and M Dieleman M Assessing health workers' revenues and coping strategies in Nigeria - a mixed-methods study. BMC Health Serv Res. 2013;13:387.

12. Statistics South Africa. Poverty trends in South Africa. [Internet]. Pretoria: Statistics South Africa; 2014. [cited 2018 Nov 11]. Available from: http://www.statssa.gov.za/?p $=2591$

13. Statistics South Africa. Poverty on the rise in South Africa. [Internet] Pretoria: Statistics South Africa; 2017. [cited 2018 Nov 11]. Available from: http://www.statssa.gov.za/?p=10334

14. Web centre for social research methods. Research methods knowledge base - reliability and validity. [cited 2015 March 19]. Available from: http://www.socialresearchmethods.net/kb/relandval.php

15. Parlamentary Monitoring Group. Human resources \& community health workers: Gauteng, Mpumalanga, North West; Infrastructure projects; Financial management; Ideal Clinic Initiative. [Internet.] 2016 [cited 2028 Dec 13]. Available from: https://pmg.org.za/ committee-meeting/23079/

16. Statistics South Africa. Gender Statistics South Africa, 2011. [Internet]. Pretoria: Statistics South Africa; 2011. [cited 2018 Nov 11]. Available from: http://www.statssa.gov.za/publications/Report-03-10-05/ Report-03-10-052011.pdf

17. Geldsetzer P, De Neve W, Boudreaux C, Barnighausen T, Bossert TJ. Improving the performance of community health workers in Swaziland: findings from a qualitative study. Hum Resour Health. 2017; 15:68

18. Janicijevic I, Seke K, Djokovic A, Filipovic T. Healthcare workers satisfaction and patient satisfaction - where is the linkage? Hippokratiav. 2013;17(2):157-62.

19. Johnson R. Key reasons for job dissatisfaction and poor employee performance. 2018 [cited 2019 April 1]. Available from: https:// smallbusiness.chron.com/key-reasons-job-dissatisfaction-pooremployee-performance-25846.html

20. Akwataghibe N, Samaranayake D, Lemiere C, Dieleman M. Assessing health workers' revenues and coping strategies in Nigeria - a mixed-methods study. BMC Health Serv Res. 2013;13:387. https:// doi.org/10.1186/1472-6963-13-387

21. Kashko AN. Remuneration of community health care workers: a recommendation to the World Health organization. [Internet]. 2013 [cited 2017 Jan 17]. Available from: http://www.chwcentral.org/ sites/default/files/AKaschko_CE_0.pdf

22. Mpembeni RNM, Bhatnagar A, LeFevre A, Chitama D, Urassa DP, Kilewo $C$, et al. Motivation and satisfaction among community health workers in Morogoro region, Tanzania: nuanced needs and varied ambitions. Hum Resour Health. 2015;13:44. https://doi.org/10. 1186/s12960-015-0035-1 